\title{
A INSERÇÃO DA TRAJETÓRIA HIPOTÉTICA DE APRENDIZAGEM NA EDUCAÇÃO A DISTÂNCIA: RELATO DE PRÁTICAS REALIZAS EM UM CURSO DE LICENCIATURA EM MATEMÁTICA.
}

\author{
LONDRINA/PR MAIO/2018
}

\author{
Diego Fogaça Carvalho - UNOPAR - diego.fogaca@kroton.com.br \\ Renata Karoline Fernandes - UNOPAR - renata.karoline@kroton.com.br \\ Hallynnee Héllenn Pires Rossetto - UNOPAR - hallynnee.rossetto@kroton.com.br \\ Daiany Cristiny Ramos - UNOPAR - daiany.ramos@unopar.br \\ Alessandra Negrini Dalla Barba - UNOPAR - alessandra.barba@kroton.com.br \\ Mariana da Silva Nogueira Ribeiro - UNOPAR - mariana.snogueira@kroton.com.br \\ Adriana Giarola Ferraz Figueiredo - UNOPAR - adriana.gfigueiredo@kroton.com.br
}

Tipo: Relato de Experiência Inovadora (EI)

Categoria: Conteúdos e Habilidades

Setor Educacional: EDUCAÇÃO SUPERIOR

\section{RESUMO}

Neste relato, temos por objetivo apresentar as práticas que desenvolvemos no curso de Licenciatura em Matemática, na modalidade EaD, que versam à inserção da Trajetória Hipotética de Aprendizagem (THA). No quinto semestre, essa temática é abordada na disciplina de Metodologia do Ensino da Matemática, possibilitando reflexões sobre seus pressupostos teóricos e exemplificando sua realização. No sexto semestre, os estudos são aprofundados, por meio da disciplina Estágio Curricular Obrigatório III e, por fim, no último semestre, na disciplina de Projeto de Ensino, os estudantes sintetizam e aplicam seus conhecimentos na elaboração de uma THA em forma de artigo. Em suma, compreendemos que a THA é um processo que proporciona ao futuro professor, não somente refletir sobre o conteúdo matemático e a forma como irá abordá-lo em sala de aula, sendo necessário, também, levantar hipóteses a respeito das diferentes formas como os alunos lidarão com esse conteúdo durante o processo de aprendizagem.

Palavras-chave: Educação Matemática; Trajetória Hipotética de Aprendizagem; Educação à Distância

\section{AGRADECIMENTOS}

AGRADECEMOS À EQUIPE DE PROFESSORES DO CURSO DE LICENCIATURA EM MATEMÁTICA DA UNIVERSIDADE PITÁGORAS UNOPAR 


\section{Introdução}

O curso de Licenciatura em Matemática, na modalidade EaD, tem por objetivo capacitar o estudante para o trabalho docente, por meio do domínio da natureza do conhecimento matemático, sua produção e difusão, além de promover formação teórica e prática, com vista à formação do profissional participativo na sociedade. Uma maneira de realizar essa capacitação do estudante acontece por meio do uso de metodologias.

A Trajetória Hipotética de Aprendizagem (THA) é uma das metodologias utilizadas nas práticas do curso, nas disciplinas de Metodologia do Ensino da Matemática, Estágio Curricular Obrigatório III e Projeto de Ensino, promovendo a configuração de um ambiente de aprendizagem, que vai além da elaboração dos tradicionais planejamentos, pautados nos procedimentos relativos ao processo de ensino. A THA procura possibilitar ao professor levantar hipóteses a respeito da maneira como os alunos lidam com 0 conteúdo matemático no processo de aprendizagem, exigindo do docente a mobilização de conhecimentos relacionados à maneira como concebe a aprendizagem de seus alunos.

Na primeira parte do artigo, é apresentado como essa metodologia pode ser entendida e qual a sua importância para o professor. Em seguida, traz-se a maneira como a THA foi abordada nas disciplinas do curso. Por fim, são abordadas reflexões a respeito da importância dessa metodologia para um curso de licenciatura em Matemática.

\section{A Trajetória Hipotética de Aprendizagem}

A Trajetória Hipotética de Aprendizagem pode ser entendida como um planejamento bem detalhado que o professor utiliza para orientar seu trabalho em sala de aula.

O termo Trajetória Hipotética de Aprendizagem foi utilizado por Martim Simon (1995) para se referir tanto

"[...] à previsão do professor como para a trajetória que possibilitará a aprendizagem. É hipotética, porque a verdadeira trajetória de aprendizagem não é cognoscível de antecedência. Isso caracteriza uma expectativa. A aprendizagem individual dos estudantes ocorre de forma idiossincrática, embora muitas vezes em trajetos semelhantes" (SIMON, 1995, p. 135).

O professor, ao elaborar uma THA, faz uma previsão do seu trabalho em sala de aula. É uma previsão, pois ele não sabe, realmente, o que irá acontecer. Ao delinear caminhos, 
ele constrói um projeto de decisões que pode ser modificado ao longo dessa trajetória: "Mesmo que o professor desenvolva um plano para sala de aula, ele poderá ser repensado, modificado, pois as interações professor e aluno e as observações do professor fazem com que isso ocorra" (ROSSETTO, 2016, p. 24-25).

Segundo Traldi Jr e Rosembaum (2010, p. 374)

"A trajetória se refere aos caminhos que os alunos devem seguir para a construção dos conhecimentos pretendidos. [...] o termo "hipotético" compreende duas perspectivas: a que entende que o professor tem acesso apenas às hipóteses dos conhecimentos dos alunos, isto é, não consegue acessar diretamente o conhecimento dos aprendizes e a outra perspectiva, para fazer referência ao prognóstico, à expectativa do professor, a respeito de como a aprendizagem será processada pelos alunos".

A THA é constituída por três componentes:

"1. o objetivo do professor com direções definidas para a aprendizagem de seus alunos; 2. as tarefas de ensino; 3. o processo hipotético de aprendizagem (SIMON, 1995, p. 136)".

O professor, ao construir uma THA, precisa, primeiramente, definir os objetivos que pretende alcançar, qual o seu propósito e o que ele quer que o aluno aprenda. Após definido o objetivo, ele precisa selecionar tarefas que o auxiliarão a cumprir seu propósito inicial. Essas tarefas podem ser elaboradas pelo professor ou retiradas de materiais. Por fim, ele descreve a resolução dessas tarefas, abordando suposições e questionamentos do pensamento e do entendimento dos alunos.

Elaborar uma THA permite ao professor pensar nas possíveis perguntas e dúvidas dos alunos, possibilitando uma maior segurança no trabalho em sala de aula, pois ele se preparou para possíveis situações que podem ocorrer.

\section{Objetivo do trabalho}

Este relato tem por objetivo apresentar as práticas que desenvolvemos no curso de Licenciatura em Matemática da Universidade Pitágoras Unopar - UNOPAR, na modalidade Educação a Distância, que versam à inserção da Trajetória Hipotética de Aprendizagem (THA), principalmente no ano de 2017, em diversos momentos do curso. 
As experiências que apresentamos, ao longo deste relato, pautam-se na descrição detalhada dos fatos, de caráter qualitativo, e tem por objetivo divulgar as práticas que consideramos inovadoras para o contexto da Educação a Distância. Nesse sentido, este relato apresenta, do ponto de vista metodológico, ser predominantemente qualitativo, descritivo e exploratório.

De acordo com Bogdan e Biklen (1994), a pesquisa qualitativa é descritiva, exigindo do pesquisador uma abordagem minuciosa, considerando que os fatos que acontecem não são triviais, que as situações observadas e, posteriormente, descritas, apresentam potencialidades para a análise e a compreensão do fenômeno que se procura estudar. Para esses autores, a descrição é compreendida como um método de recolha e de análise de dados quando se tem por intuito apresentar os detalhes inerentes ao fenômeno investigado.

\section{A Trajetória Hipotética de Aprendizagem nas disciplinas do curso}

A Trajetória Hipotética de Aprendizagem é tratada em três momentos do curso: em um primeiro momento, na disciplina de Metodologia do Ensino da Matemática, posteriormente, na disciplina de Estágio Curricular Obrigatório III e, por fim, na disciplina Projeto Integrador.

A disciplina de Metodologia do Ensino da Matemática, no curso, acontece no 5ำ semestre, e tem por objetivo mostrar ao estudante estratégias para o ensino de Matemática. São abordados temas como a importância do planejamento, por parte do professor, a avaliação e algumas metodologias do ensino da Matemática. Na aula sobre planejamento, são evidenciadas características de um plano de aula e sua importância para o professor de Matemática. As aulas também abordaram metodologias do ensino da Matemática, como a resolução de problemas, a investigação matemática e a abordagem da Educação Matemática.

A Trajetória Hipotética de Aprendizagem é apresentada e discutida em uma das aulas como uma metodologia. Nesse momento, são apresentados os principais elementos da THA e a diferença existente entre o plano de aula e a THA. Uma THA sobre a tarefa as macieiras (FERNANDES; PIRES, 2013) é abordada na aula. A partir desse tema, são elencados os objetivos de aprendizagem, a apresentação da tarefa e são elaboradas hipóteses sobre dúvidas e soluções para ela. Além desses elementos, são apresentados os materiais necessários para o desenvolvimento da tarefa proposta. Esse exemplo permite que o estudante veja que a principal diferença entre um plano de aula e uma THA são as hipóteses levantadas pelo professor. 
No curso de Licenciatura em Matemática, uma das atividades essenciais para a formação dos futuros professores são os estágios supervisionados, os quais, segundo a Resolução $n^{\circ}$ 2, de $1^{\circ}$ de julho de 2015, em seu capítulo V, Art. 13, § 6º , correspondem a atividades obrigatórias dos currículos dos cursos de licenciatura e são articuladas com a prática e com outras atividades de trabalho acadêmico.

$\mathrm{Na}$ instituição, a carga-horária total de estágio supervisionada é dividida em três disciplinas, a saber: Estágio Curricular Obrigatório I, Estágio Curricular Obrigatório II e Estágio Curricular Obrigatório III, desenvolvidas, respectivamente, no 4ํㅜㄴ $5^{\circ}$ e $6^{\circ}$ semestres do curso de licenciatura. A primeira disciplina de estágio supervisionado é voltada a um contato inicial com as instituições de ensino da Educação Básica, sendo as atividades direcionadas, principalmente, ao reconhecimento do campo de estágio, estudo de Projetos Políticos Pedagógicos, legislações, visando principalmente à observação de turmas dos anos finais do Ensino Fundamental e possibilitando reflexões a respeito do papel do professor nessa etapa. No Estágio Curricular Obrigatório II, além das observações nos anos finais do Ensino Fundamental e os estudos teóricos complementares, têm início as atividades de intervenção pedagógica, ou seja, a regência na etapa de ensino citada, o que exige do estagiário reflexões a respeito da elaboração de planos de aula, de acordo com o contexto de atuação, bem como a aplicação das tarefas elaboradas e a realização de reflexões após o desenvolvimento da regência. Na disciplina de Estágio Curricular Obrigatório III, voltada ao Ensino Médio, ocorre a inserção das Trajetórias Hipotéticas de Aprendizagem em conjunto com as atividades características do estágio, como observações e intervenções práticas.

O Estágio Curricular Obrigatório III, realizado no 6ํㅗ semestre do curso de Licenciatura em Matemática, tem por objetivo propiciar ao estagiário um ambiente oportuno para a realização de reflexões e investigações a respeito das especificidades do ensino de Matemática no Ensino Médio. Nessa etapa do curso, o estagiário já vivenciou o cotidiano das instituições de Educação Básica, conheceu sua estrutura básica, refletiu a respeito da importância do estágio supervisionado para sua formação, construiu planos de aula para a intervenção pedagógica em turmas dos anos finais do Ensino Fundamental e, concomitantemente, cursou disciplinas voltadas à organização do trabalho pedagógico, como é o caso de Metodologia do Ensino da Matemática e Tecnologias no Ensino da Matemática, por exemplo, o que possibilitou a ele refletir a respeito de como o professor pode organizar seu trabalho, considerando as particularidades do ensino da Matemática nas diferentes etapas de ensino. Sendo assim, o estagiário já dispõe de conhecimentos em relação a esses temas, o que favorece o desenvolvimento de sua última disciplina de estágio. 
Considerando o contexto descrito anteriormente, e a experiência que o estagiário já possui em relação a essa atividade prática, no Estágio Curricular Obrigatório III, algumas atividades foram construídas com ênfase no estudo e na elaboração de Trajetória Hipotética de Aprendizagem (THA) como forma de preparação para a regência e, consequentemente, contribuindo para sua formação enquanto futuro professor de Matemática.

Uma das atividades a serem desenvolvidas na disciplina citada corresponde à análise de uma proposta visando ao reconhecimento dos elementos que compõem as THAs. Assim, nesse caso, com base em um estudo teórico, o estagiário deve analisar uma proposta de trabalho relativa ao tema "função", justificando se esta pode ser classificada como uma THA e, em caso negativo, que elementos estariam ausentes e que impossibilitam a classificação enquanto THA. Dessa forma, além de conhecer as características desse tipo de plano, os estagiários precisam estar aptos a reconhecê-las ou a complementar propostas de modo a transformá-las em trajetórias.

Além desse estudo teórico, uma das principais atividades do Estágio Curricular Obrigatório III diz respeito à elaboração de uma Trajetória Hipotética de Aprendizagem para aplicação na regência, a qual é direcionada para uma das turmas do Ensino Médio, diferindo assim da proposta da disciplina de estágio supervisionado do $5^{\circ}$ semestre, cujo objetivo era a elaboração de um plano de aula para desenvolvimento da intervenção prática.

A opção pela Trajetória Hipotética de Aprendizagem para ○ Estágio Curricular Obrigatório III deu-se a partir de reflexões sobre a necessidade de reflexões prévias, por parte do estagiário, como forma de preparação para a regência. Nesse sentido, além de elaborar as tarefas, com base em um tema adequado ao ano selecionado para desenvolvimento da regência, o estagiário deve refletir sobre as possíveis soluções para as tarefas elaboradas, bem como sobre possíveis dúvidas que podem ser manifestadas pelos alunos ao longo do desenvolvimento das tarefas, e possíveis intervenções que podem ser adotadas no caso das dúvidas elencadas serem manifestadas. Com isso, o estagiário busca prever determinados questionamentos e dúvidas como uma forma de se preparar para as situações inusitadas que podem ocorrer durante a intervenção prática.

Por mais que não seja possível, ao estagiário, prever todas as situações que podem surgir durante a regência, esse tipo de estudo pode contribuir em sua preparação para lidar com os imprevistos que podem surgir nesse momento, sendo este um elemento integrante do cotidiano do professor, independentemente da etapa de atuação. Com 
isso, pretende-se que o estudante, desde a graduação, inicie a aquisição do hábito de refletir a respeito das tarefas elaboradas por ele em sua carreira profissional, buscando identificar tópicos e problemas que podem acarretar dúvidas, o que irá contribuir com a elaboração de propostas mais significativas aos alunos e que possam favorecer seu desenvolvimento, aperfeiçoando, cada vez mais, sua prática, de modo a possibilitar aos seus alunos, ou futuros alunos, uma aprendizagem significativa em Matemática.

\section{A Trajetória Hipotética de Aprendizagem no projeto de ensino}

De acordo com Gauthier et al. (1998), o ofício do professor é composto por vários saberes, no sentido figurado a de um reservatório. Nesse sentido, o professor se abastece com o objetivo de responder às exigências advindas de sua prática de ensinar. Para esse autor, o reservatório de saberes docentes é composto da seguinte forma: saberes disciplinares - a matéria; saberes curriculares - o programa; saberes da ciência da educação; saberes da tradição pedagógica - o uso; saberes experienciais - a jurisprudência particular; saberes da ação pedagógica - o repertório de conhecimentos do ensino ou a jurisprudência pública validada. Como qualquer profissional, o professor "age em função de ideias, de motivos, de projetos, de objetivos, em suma, de intenções ou razões das quais ele está 'consciente' e que ele pode geralmente justificar" (TARDIF, 2014, p. 208).

Fundamentando-se nesses conceitos, o projeto de ensino refere-se a uma das atividades de conclusão do curso de Licenciatura em Matemática, em que o estudante deve elaborar uma produção científica, um artigo. Um dos objetivos dessa tarefa é oportunizar um processo reflexivo para que o aluno possa articular os saberes advindos de sua vivência em sala de aula com o conhecimento científico produzido da área da Educação Matemática, em um contexto de pesquisa.

Em suma, tem-se a intenção de contribuir com a formação do pensamento críticoreflexivo, de modo que o aluno possa realizar a articulação entre prática e teoria, assumindo a sala de aula da Educação Básica (Ensino Fundamental e Médio) como contexto a ser problematizado e reconstruído por meio do pensamento analítico possibilitado pela pesquisa.

Diante desse contexto, a Trajetória Hipotética de Aprendizagem se configura uma fundamentação teórica pertinente para os objetivos almejados, principalmente pela necessidade de articulação entre as intenções do professor para com a aprendizagem do aluno, seu plano para as atividades de aprendizagem, bem como a elaboração de hipóteses a respeito do processo de aprendizagem da matemática dos alunos. Em 
suma, os processos reflexivos oportunizados pela realização de uma THA contribuem para a racionalização do trabalho docente, possibilitando ao professor alinhar suas ações com os objetivos da escola, contribuindo com o cumprimento da missão social da instituição.

Com a elaboração de uma THA, o futuro professor pode refletir sobre os saberes disciplinares e a maneira como os compreende, bem como os objetivos de ensiná-los, mobilizando saberes curriculares. Na sequência, é possível questionar esses objetivos, rompendo com visões que se solidificaram ao longo do tempo no ensino da Matemática, possibilitando uma ressignificação de acordo com as demandas atuais da sociedade.

Em seguida, ele pode refletir sobre as tarefas matemáticas pertinentes para alcançar os objetivos traçados. Essas tarefas podem ser adaptadas, sendo reestruturadas pelas hipóteses elaboradas pelo professor a respeito da maneira como compreende que seus alunos aprendem Matemática. Nesse momento, o futuro professor é levado a pensar sobre seus saberes experienciais e sobre os saberes da ação pedagógica, podendo ou não, articular esse processo reflexivo com os saberes das ciências da educação, elaborando uma trajetória que tem por objetivo explicitar a maneira como os alunos fictícios, mas com lastro à perspectiva construída, podem aprender.

O projeto organizado pelo estudante E1 está inserido no contexto da educação financeira, o que já denota que o estudante se valeu de uma demanda social atual, pois se faz necessário, na sociedade contemporânea, o desenvolvimento de habilidades relacionadas ao planejamento financeiro.

1) Fazer com que seja perceptível que em momentos de crise, é muito importante buscar aumentar a renda familiar mensal e pessoal, pois isso corresponde a um dinheiro a mais no final de cada mês para cada família. Assim todos colaboram, dando maior força no orçamento da família, para ninguém chegar ao final do mês em dividas, e sim com todas as contas pagas e ainda algum dinheiro sobrando. Além das propostas demonstrarem que cuidando da renda familiar da melhor maneira possível, os alunos entenderem, que pode ser feito melhores compras de coisas pessoais ou para benefício familiar com o salário planejado.

Fragmento extraído da $3^{\circ}$ tarefa apresentada pelo Estudante E1.

As tarefas geraram uma sequência de situações que partiam de uma tomada de conhecimento do destino financeiro da receita familiar, seguida de uma reflexão sobre os gastos familiares e uma reestruturação do orçamento, o que possibilitou a realização 
de um planejamento financeiro, no qual toda a família possa contribuir. No trecho apresentado, que se refere ao objetivo da terceira tarefa, é perceptível o cuidado que o estudante apresentou em se valer do momento econômico vivenciado pelo Brasil na elaboração de sua proposta. Na continuidade são apresentadas algumas considerações finais.

\section{ConsideraçõesFinais}

Este relato de experiência visou à apresentação da forma como a Trajetória Hipotética de Aprendizagem foi inserida no curso de Licenciatura em Matemática da Universidade Pitágoras Unopar, na modalidade de Ensino a Distância. Compreendemos que as práticas que foram realizadas, em torno dessa temática, configuraram-se inovadoras pela possibilidade de reflexão da ação intelectual realizada pelo aluno no processo de aprendizagem, superando a visão tradicional de planejamento, que se centra nas ações de ensino, pautadas no professor.

Ao trazer para o processo de formação as diversas maneiras pelas quais os alunos podem aprender, mesmo sendo esse aluno uma construção fictícia, mas com lastro nas concepções e crenças apresentadas pelo futuro professor sobre quem são e como os alunos podem aprender, a THA se configurou uma oportunidade de aprendizagem sobre a docência por possibilitar a confluência de diversos saberes que são indispensáveis para a prática pedagógica, principalmente o alinhamento entre o conteúdo matemático e as diversas formas de abordagem desse conteúdo.

Todavia, há um grande caminho para ser percorrido, principalmente pelo fato de os futuros professores não estarem habituados com situações que apresentam essas características. Muitas foram as vezes em que os tutores solicitaram aos professores como deveriam proceder na correção, pois o trabalho enviado pelo acadêmico se resumiu a um plano de aula. Visando à superação desse fato, compreende-se que, pontualmente, há necessidade de promover um processo de problematização da produção realizada pelo aluno, com o intuito de desencadear um processo reflexivo sobre as diversas maneiras que o aluno pode aprender. Por outro lado, pensando em longo prazo, a maneira como a THA foi inserida no curso, sendo sua abordagem distribuída ao longo dos semestres letivos, refere-se a uma estratégia de institucionalização, tornando-a cada vez mais familiar para o futuro professor.

\section{Referências}

BOGDAN, R. C.; BIKLEN, S. K. Investigação qualitativa em educação. Trad. Maria J. 
Alvez, Sara B. dos Santos e Telmo M. Baptista. Porto: Porto Editora, 1994.

BRASIL. Conselho Nacional de Educação. Resolução CNE/CP 02/2015. Diretrizes Curriculares Nacionais para a formação inicial em nível superior (cursos de licenciatura, cursos de formação pedagógica para graduados e cursos de segunda licenciatura) e para a formação continuada. Brasília: CNE. 2015.

FERNANDES, R. K. PIRES, M. N. Uma Trajetória Hipotética de Aprendizagem: Construindo o Pensamento Algébrico nos Anos Iniciais. In: XI Encontro Nacional de Educação Matemática, 2013, Curitiba. Anais..., 2013

GAUTHIER, Clemont; MARTINEAU, Stéphane; DESBIENS, Jean-François; MALO, Annie; SIMARD, Denis. Por uma teoria da pedagogia: pesquisas contemporâneas sobre o saber docente. ljuí: Unijuí/RS, 2013.

ROSSETTO, Hallynnee Héllenn Pires. Trajetória Hipotética de Aprendizagem sob um olhar realístico. 2016. 104f. Dissertação (Mestrado em Ensino de Ciências e Educação Matemática) - Universidade Estadual de Londrina, Londrina, 2016.

SIMON, M. A. Reconstructing mathematics pedagogy from a constructivist perspective. Journal for Research in Mathematics Education, vol. 26, n. 2, pp. 114-145. 1995.

TARDIF, Maurice. Saberes docentes e formação profissional. Petrópolis/RJ: Vozes, 2014.

TRALDI JR, Armando; ROSENBAUM, Luciane Santos. Uma trajetória hipotética de aprendizagem sobre funções trigonométricas numa perspectiva construtivista. Educação Matemática Pesquisa, v. 12, n. 2, 2010. 